\title{
Defining Criteria for Macrophage Activation Syndrome, a Process Towards Early Recognition and Treatment
}

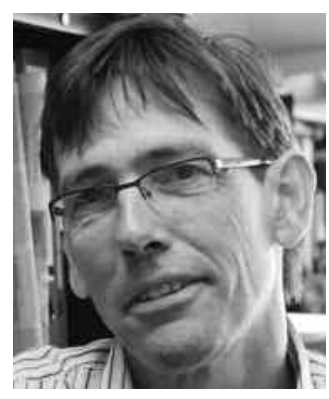

Systemic juvenile idiopathic arthritis (sJIA) is a heterogeneic disease of unknown pathogenesis. Some $20 \%$ of cases have a monophasic and very mild disease course, in contrast to the other extreme subtype with chronic relapsing systemic features and progressive polyarthritis. The majority of cases have systemic features mainly in the early phase of the disease but often develop a severe destructive polyarthritis later. Since its original description in 1890 by Mayer Diamantberger in Hôpital Rothschild in Paris, France ${ }^{1}$, and in 1897 by George Frederick Still in England, sJIA is still defined by the classic triad of spiking fever of at least 2 weeks' duration, arthritis, and one of the following symptoms: typical exanthema, lymphadenopathy, hepatosplenomegaly, or ascites ${ }^{2}$.

Recent laboratory studies identified key cytokines such as interleukin 1 (IL-1), IL-6, and IL-18, as well as natural killer (NK) cell dysfunction that cannot be found in any other subtype of JIA ${ }^{3,4,5,6}$. The heterogeneity is further illustrated by description of cases with spiking fever, exanthema associated with this typical cytokine pattern, and NK cell dysfunction but without arthritis. In fact, sJIA can be viewed as an autoinflammatory disease rather than an autoimmune disease.

Macrophage activation syndrome (MAS) is a potentially lethal condition that can occur in association with a variety of conditions. Among the rheumatic diseases, MAS occurs most frequently in SJIA. It is viewed by some as representing the extreme end of the spectrum of sJIA ${ }^{7}$. Description of the typical features of MAS is even more challenging, since MAS can also occur in association with other inflammatory diseases ${ }^{8}$. It can occur in previously healthy individuals with or without evidence of a viral infection, or as a variety of monogenetic diseases, called hereditary lymphohistiocytosis (HLH). It is identical to a syndrome called virus-associated hemophagocytic syndrome (VAHS), well described in malignant disorders treated with immunosuppressive drugs. A wide range of clinical and laboratory symptoms has been attributed to MAS, adding to its complexity. Most physicians view the hemophagocytosis in bone marrow, central nervous system fluid, or spleen as the key feature for this syndrome, although many severe MAS cases have been described without overt bone marrow hemophagocytosis. By contrast, hemophagocytosis can also be found in the absence of clinically overt MAS. This raises the question of whether the hemophagocytosis reflects an important aspect in the etiopathogenesis of MAS or just an epiphenomenon.

Treatment usually consists of corticosteroids and cyclosporine. In more severe cases etoposide is added (HLH protocol) $)^{9}$. Anakinra has been described as both cause and treatment for this complication ${ }^{10}$. In 2004 Ravelli, et al summarized the frequency of clinical, laboratory, and histopathological symptoms of MAS in sJIA in a review of 57 published cases and 17 cases from their own institute ${ }^{8}$. Of the clinical features only fever and hepatomegaly were present in more than 50\% of reported cases. Lowered platelets and erythrocyte sedimentation rate were present in more than $90 \%$ of reported cases, and hyperferritinemia $(>10,000 \mu \mathrm{g} / \mathrm{l})$ was reported in a minority of cases. There is, however, a significant publication bias because these published cases represent only a minority of prevalent cases. Given the widespread use of anakinra in the maintenance treatment of sJIA, it can be expected that we will see attenuated cases of MAS developing under anakinra treatment ${ }^{11,12}$. This may further complicate accurate and early recognition of this complication. The latter is important given the reported mortality rate of between $8 \%$ and $22 \%$.

A report in this issue by Davi, et al is of interest because the authors address this issue on a much larger scale ${ }^{13}$. The article aims to confirm the candidate variables of MAS described by Ravelli as relevant for early recognition ${ }^{8}$. They ranked the symptoms by degree of importance according to the opinion of the vast majority of experienced pediatric rheumatologists in both the Americas and Europe. Democracy reigns. In a simple questionnaire, 232 pediatric

See International consensus survey of diagnostic criteria for MAS in systemic JIA, page 764

Personal non-commercial use only. The Journal of Rheumatology Copyright @ 2011 . All rights reserved. 
rheumatologists representing 27 countries were asked to select their top 10 criteria from a list of 32 items. The most frequently selected items were the clinical feature "continuous fever" and 9 simple laboratory tests that are widely available. Also in their study, fever and progressive thrombocytopenia belonged to the top 10 criteria. In contrast to the earlier study, hyperferritinemia was now ranked high. The well known histopathological feature of hemophagocytosis scored high in both studies. Of note, there are more specific immunological tests indicative of T cell, NK, and macrophage activation such as soluble IL-2 receptor and soluble CD163, but these were ranked lower on the list. Use of the latter tests has been restricted to academic centers with a specific interest in SJIA or HLH. CD163 is a scavenger receptor for hemoglobin-haptoglobin complexes, stimulating pathways for adaptation to oxidative stress induced by free iron. CD163-positive macrophages can be found in patients with sJIA, perhaps representing early or subclinical stages of MAS ${ }^{6,14}$. Recently, gene expression studies linked expansion of these macrophages to distinct signatures ${ }^{14,15}$. Especially in subclinical or attenuated forms of MAS (anakinra-treated cases) such additional tests could be of value.

However, first the selected candidate diagnostic criteria must be tested in evaluating a large cohort of case histories (part 2 of this validation procedure). This is essential because many of the items chosen occur commonly in "simple" sJIA. The validating procedure would hopefully yield the main differentiating features. Delphi consensus formation yields a validated tool for classification, description of disease activity, and response to treatment. This method for evaluation of disease variables was used earlier in joint studies of the American and European pediatric rheumatology organizations Childhood Arthritis and Rheumatology Research Alliance (CARRA), Paediatric Rheumatology Collaborative Study Group (PRCSG), and Paediatric Rheumatology INternational Trials Organization (PRINTO). It provided disease activity and remission criteria for JIA, systemic lupus erythematosus, and juvenile dermatomyositis that are nowadays widely used as key outcome variables in clinical studies. A similar set of criteria for MAS would facilitate evaluation of disease severity and response to treatment, using a more uniform treatment strategy. It will be up to PRINTO and CARRA to prepare such proposals.

NICO M. WULFFRAAT, MD,

Department of Pediatrics, Subunit Pediatric Rheumatology, University Medical Center Utrecht, PO Box 85090, 3808AB Utrecht, The Netherlands

\section{REFERENCES}

1. Diamantberger MS. Du rhumatisme noueux (polyarthrite deformante) chez les enfants [thesis]. University of Paris; 1891. [Internet. Accessed January 11, 2011.] Available from: http:// worldcat.org/oclc/14782325

2. Still GF. On a form of chronic joint disease in children. Med Chir Trans 1897;80:47-59.

3. Allantaz F, Chaussabel D, Stichweh D, Bennett L, Allman W, Mejias A, et al. Blood leukocyte microarrays to diagnose systemic onset juvenile idiopathic arthritis and follow the response to IL-1 blockade. J Exp Med 2007;204:2131-44.

4. de Jager W, Hoppenreijs EPAH, Wulffraat NM, Wedderburn LR, Kuis W, Prakken BJ. Blood and synovial fluid cytokine signatures in patients with juvenile idiopathic arthritis: a cross-sectional study. Ann Rheum Dis 2007;66:589-98.

5. de Jager W, Vastert SJ, Beekman JM, Wulffraat NM, Kuis W, Coffer PJ, et al. Defective phosphorylation of interleukin-18 receptor beta causes impaired natural killer cell function in systemic-onset juvenile idiopathic arthritis. Arthritis Rheum 2009;60:2782-93.

6. Grom AA, Villanueva J, Lee S, Goldmuntz EA, Passo MH, Filipovich A. Natural killer cell dysfunction in patients with systemic-onset juvenile rheumatoid arthritis and macrophage activation syndrome. J Pediatr 2003;142:292-6.

7. Ramanan AV, Schneider R. Macrophage activation syndrome what's in a name! J Rheumatol 2003;30:2513-6.

8. Ravelli A, Magni-Manzoni S, Pistorio A, Besana C, Foti T, Ruperto $\mathrm{N}$, et al. Preliminary diagnostic guidelines for macrophage activation syndrome complicating systemic juvenile idiopathic arthritis. J Pediatr 2005;146:598-604.

9. Henter JI, Horne A, Arico M, Egeler RM, Filipovich AH, Imashuku S, et al. HLH-2004: Diagnostic and therapeutic guidelines for hemophagocytic lymphohistiocytosis. Pediatr Blood Cancer 2007;48:124-31.

10. Miettunen PM, Narendran A, Jayanthan A, Behrens EM, Cron RQ. Successful treatment of severe paediatric rheumatic disease-associated macrophage activation syndrome with interleukin-1 inhibition following conventional immunosuppressive therapy: case series with 12 patients. Rheumatology 2011;50:417-9.

11. Nigrovic PA, Mannion M, Prince FH, Zeft A, Rabinovich CE, van Rossum MA, et al. Anakinra as first-line disease modifying therapy in systemic juvenile idiopathic arthritis. Arthritis Rheum 2010 Nov 4. [Epub ahead of print]

12. Swart JF, Barug D, Mohlmann M, Wulffraat NM. The efficacy and safety of interleukin-1-receptor antagonist anakinra in the treatment of systemic juvenile idiopathic arthritis. Expert Opin Biol Ther 2010;10:1743-52.

13. Davi S, Consolaro A, Guseinova D, Pistorio A, Ruperto N, Martini A, et al. An international consensus survey of diagnostic criteria for macrophage activation syndrome in systemic juvenile idiopathic arthritis. J Rheumatol 2011;38:764-8.

14. Behrens EM, Beukelman T, Paessler M, Cron RQ. Occult macrophage activation syndrome in patients with systemic juvenile idiopathic arthritis. J Rheumatol 2007;34:1133-8.

15. Grom AA, Mellins ED. Macrophage activation syndrome: advances towards understanding pathogenesis. Curr Opin Rheumatol 2010;22:561-6.

J Rheumatol 2011;38:593-4; doi:10.3899/jrheum.101269

Address correspondence to Dr Wulffraat;

E-mail:n.wulffraat@umcutrecht.nl

Personal non-commercial use only. The Journal of Rheumatology Copyright (c) 2011. All rights reserved. 